\title{
Notes on the vocalizations of Olive-crowned Yellowthroat (Geothlypis semiflava)
}

\section{Peter Boesman}

In the following we briefly analyze and compare voice of the two races of Olive-crowned Yellowthroat (Geothlypis semiflava). We also try to quantify the extent of any vocal differences using the criteria proposed by Tobias et al. (2010), as a support for taxonomic review. We have made use of sound recordings available on-line from Xeno Canto (XC) and Macaulay Library (ML).

Song of both races seems to be quite different. A comparison, illustrated with sonograms:

\section{Central America (bairdi)}

\section{Costa Rica}
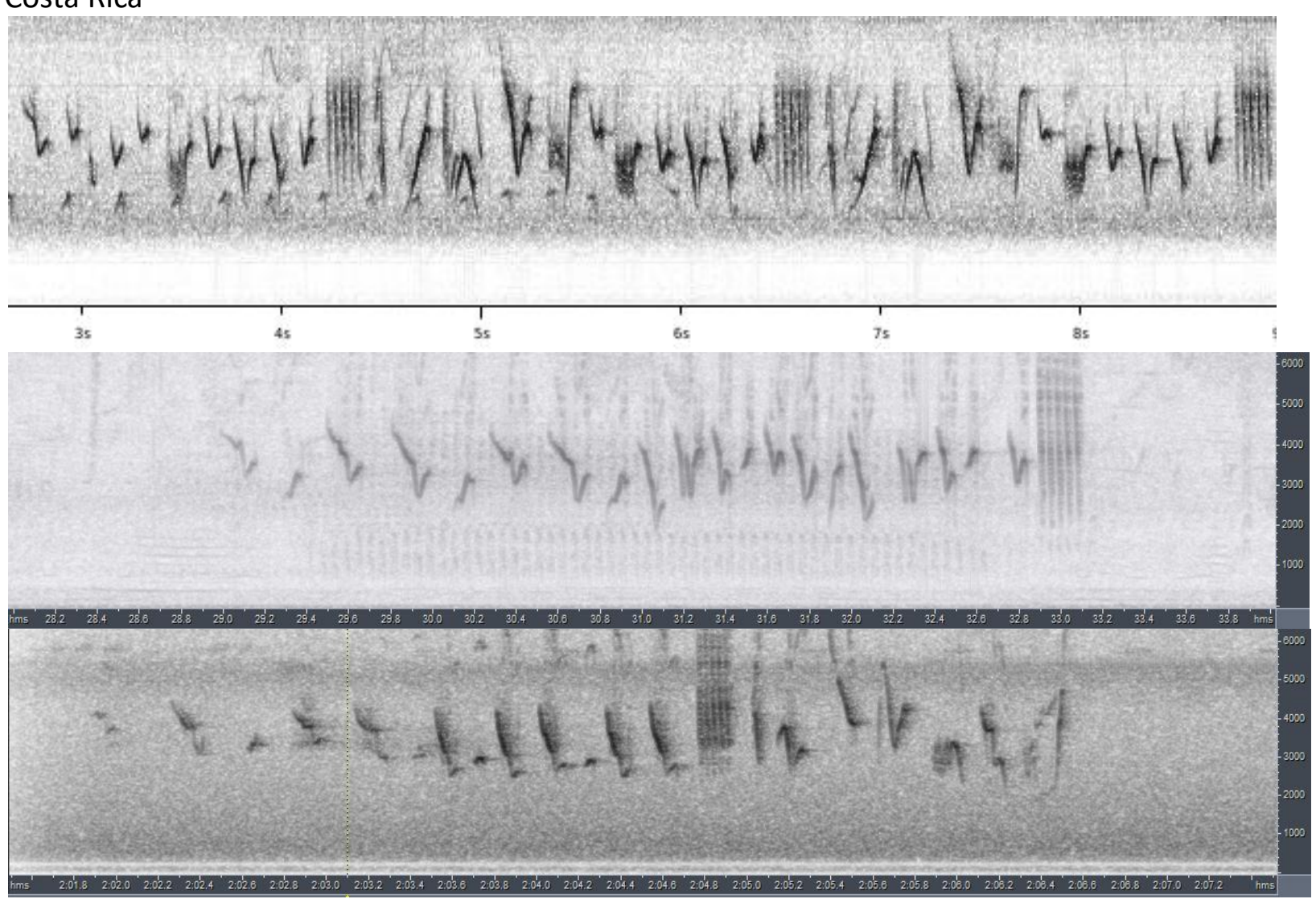

\section{Panama}

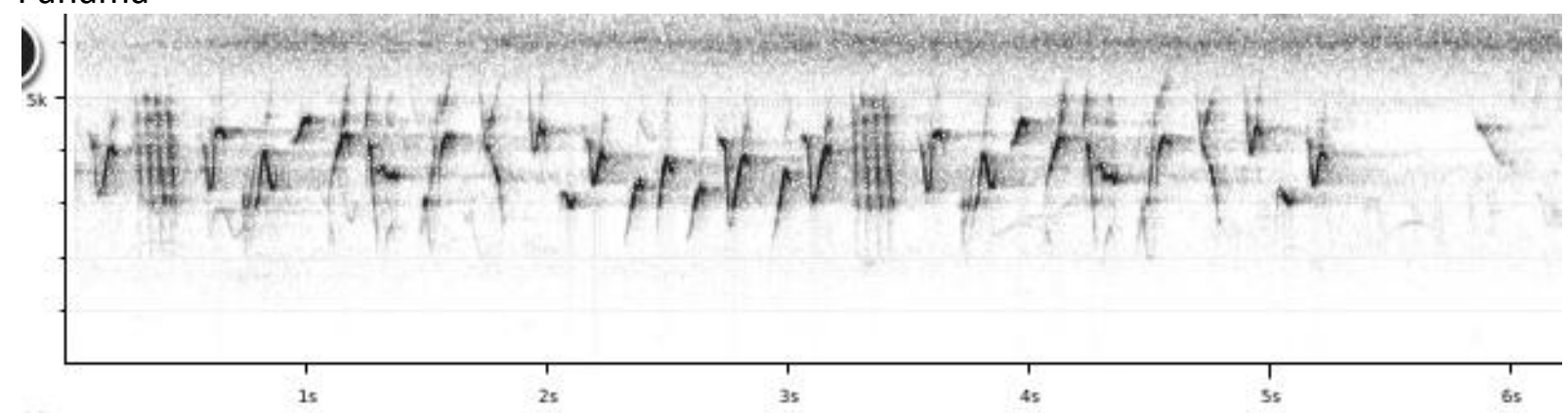



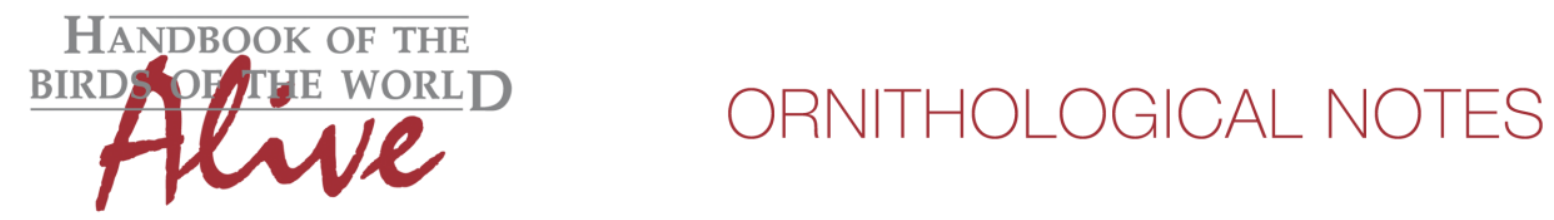

\section{South America (semiflava)}
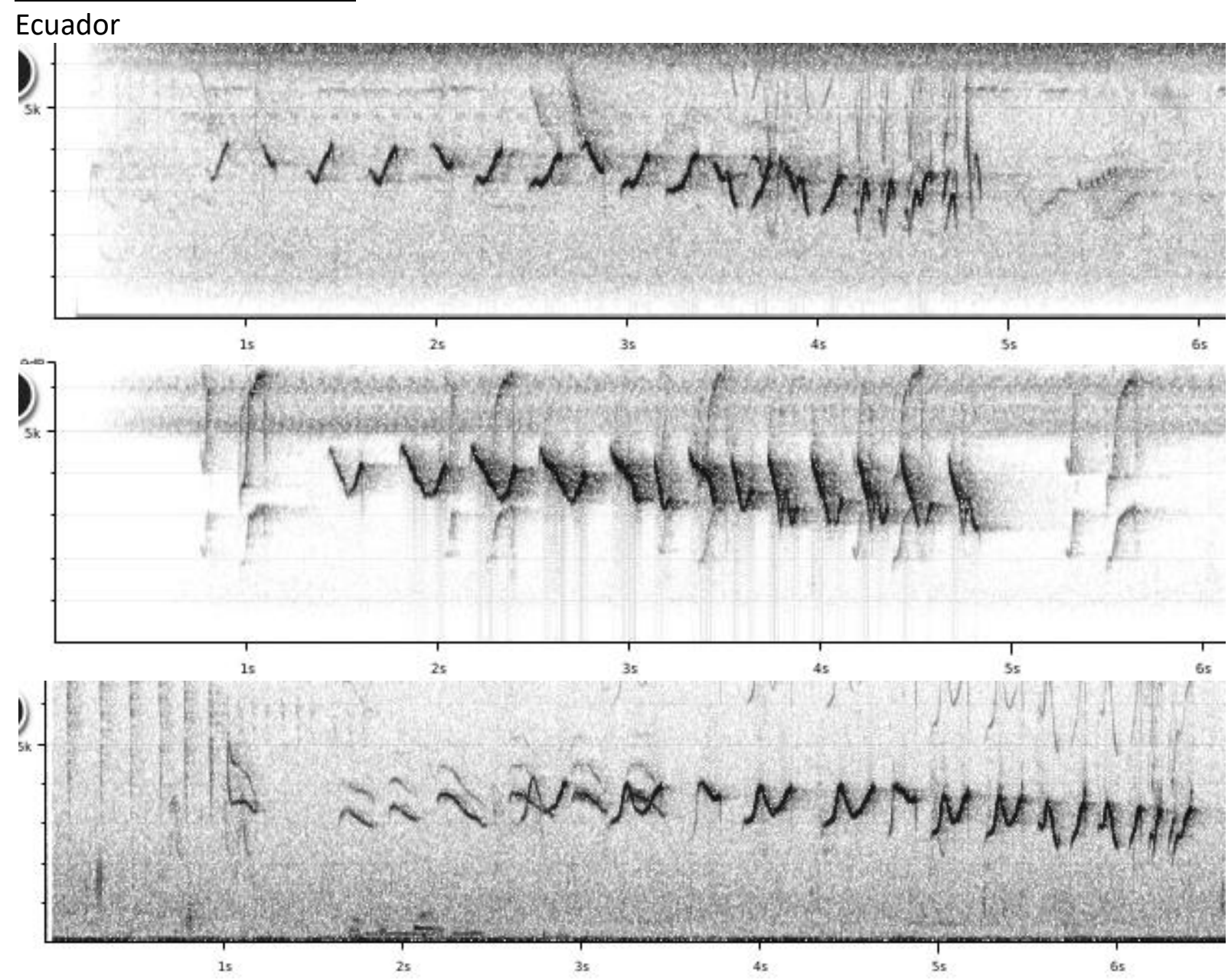

Song of nominate is a sweet somewhat dull warble with a duration of $c 3-5$ s, typically slightly descending in pitch.

Song of bairdi is a sweet vivid warble with a duration of either 4-5s or often for more prolonged periods.

Song of bairdi can be identified by the presence of (at least one) dry rattle in the song, which is never the case in nominate. Pitch is stable over the length of the song (which allows for longer extensions of song, unlike in nominate). Note shapes in nominate show gradual changes along the song phrase with hardly any pitch change between subsequent notes, in bairdi song has more varied note shapes with often clear changes in pitch between subsequent notes.

Song thus shows clear differences, which can be quantified based on e.g. nominate's lack of rattle (max. pace, score 3 ) and decrease in pitch of song phrase (minimum freq at start minus at end, score 2). When applying Tobias criteria, this would lead to a total vocal score of 5.

Analysis of calls may reveal additional vocal differences, but at present very few recordings are available for race bairdi. 
This note was finalized on 6th July 2016, using sound recordings available on-line at that moment. We would like to thank in particular the sound recordists who placed their song recordings for this species on XC and ML: Nick Athanas, Peter Boesman, Martin Cody, Paul Coopmans, Jerome Fischer, Ottavio Janni, Orlando Jarquin, Niels Krabbe, Lars Lachman, Gabriel Leite, Mitch Lysinger, Leonardo Ordoñez-Delgado, David Ross, Klemens Steiof, Joseph Tobias.

\section{References}

Tobias, J.A., Seddon, N., Spottiswoode, C.N., Pilgrim, J.D., Fishpool, L.D.C. \& Collar, N.J. (2010). Quantitative criteria for species delimitation. Ibis 152(4): 724-746.

\section{Recommended citation}

Boesman, P. (2016). Notes on the vocalizations of Olive-crowned Yellowthroat (Geothlypis semiflava). HBW Alive Ornithological Note 416. In: Handbook of the Birds of the World Alive. Lynx Edicions, Barcelona. (retrieved from http://www.hbw.com/node/1253819 on 6 December 2016). 